\title{
Teoría de la Educación, metodología y focalizaciones. La mirada pedagógica
}

\author{
José Manuel Touriñán López y Rafael Sáez Alonso (2012). \\ La Coruña (España): Netbiblo, 448 pp.
}

Es un libro oportuno, necesario, clarificador y sugerente. De estructura rigurosa, desarrolla sus tesis en nueve capítulos que, a su vez, mantienen una estructura homogénea en su desarrollo, de manera que cada uno es introducción y fundamento del siguiente, en orden a la construcción de la mirada pedagógica. Toda disciplina con autonomía funcional focaliza la realidad que estudia y genera una mentalidad específica que debe hacerse patente en la mirada hacia su objeto de estudio e intervención. La mirada muestra qué tipo de problemas conforman el trabajo disciplinar, cuál es su lenguaje específico y sus modos de prueba. Así ocurre en toda ciencia. Es pues necesario construir la mirada pedagógica respetando el carácter y sentido inherentes al significado de la Educación. Afrontar ese reto desde la disciplina pedagógica exige preguntarse acerca del papel de la teoría de la educación, la metodología y las focalizaciones que se hacen desde las mentalidades pedagógicas.

Cuando se habla de la mirada pedagógica, se quiere decir que hay que afrontar los problemas de indagación sobre la educación como problemas de la Pedagogía, no de Sociología, Psicología o Medicina; la mirada de la investigación es disciplinar.

Por ello, el libro desde la introducción a la conclusión se construye como pensamiento que permite abordar problemas de Teoría de la Educación desde una perspectiva propia del conocimiento de la Educación: la que corresponde a la mirada pedagógica que permite sistematizar modelos de intervención, respetando la complejidad de la Educación.

En esta obra se aborda la Teoría de la Educación, el Conocimiento Pedagógico y la Investigación Educativa con sentido disciplinar a través de la metodología científica, las focalizaciones y la mirada pedagógica para vindicar la importancia de la racionalidad en la construcción del conocimiento de la Educación. Se concluye que los métodos de adquisición de conocimiento y en este caso, de conoci- miento pedagógico, constituyen un objetivo esencial. Es un libro que versa sobre la metodología, es decir, sobre la forma de proceder en la racionalidad disciplinar y, especialmente, sobre la manera de construir la ciencia pedagógica y desarrollarla, fundamentando los principios de metodología (apertura, prescriptividad, pluralismo metodológico, correspondencia objetual) y los principios de investigación (objetividad del conocimiento, complejidad objetual de "educación”, autonomía funcional disciplinar, complementariedad metodológica y significación del conocimiento de la educación).

En el libro, escrito con abundantes referencias bibliográficas y vertebrado en nueve capítulos para agrupar metodología, disciplina académica, estudio, investigación, racionalidad administrativa y mirada pedagógica, se defiende la idea de que, en el mundo global en que vivimos, la Teoría de la Educación se enfrenta a una problemática compleja que exige poseer la suficiente potencia científica como para establecer parámetros acerca del conocimiento de la Educación. No se trata de vivir de los resúmenes de libros y de las investigaciones que otras ciencias han realizado, sino de resaltar la importancia de la Teoría de la Educación en la construcción de conceptos con significación intrínseca al ámbito "educación”.

Sus páginas persiguen, por consiguiente, una formación intelectual y científica de manera que se disponga un cierto orden conceptual progresivo, a través del conocimiento de las teorías y de los instrumentos lógicos de la racionalidad disciplinar que se detallan en él. La cuestión hoy no son los saberes que se transmite en la educación, sino la Educación como objeto de conocimiento.

Recensor: José Vicente Peña Calvo Universidad de Oviedo (España)

\section{Actividades prácticas de Matemáticas y su Didáctica 1}

\author{
Andrés Nortes Checa (Coord.) (2013).
}

Madrid (España): Editorial CCS, 224 pp.

Parece haber común acuerdo en que la actual concepción de competencia matemática hace referencia a lo que el individuo es capaz de hacer, acentuando por tanto el carácter instrumental de las Matemáticas: las competencias se activan al conectar el mundo real, de donde surge el problema, con las Matemáticas. En estos procesos se pueden distinguir tres dimensiones distintas: 1) Dimensión matemática (disciplinar): muestra los contenidos matemáticos concretos a los que puedan apuntar las tareas a realizar. 2) Dimensión contextual (situacional): estructura las situaciones y contextos en los que se localizan las tareas anteriores. 3) Dimensión cognitiva (indivi- 
dual): organiza las competencias que debe activar el individuo para conectar un problema del mundo real con las matemáticas que tiene que poner en juego para intentar su resolución.

En este sentido, la aportación que el profesor Nortes Checa y su equipo hacen en esta magnífica obra se nos presenta como una inestimable ayuda para los profesores de Matemáticas. Podríamos decir, como indica el título, que se trata de una recopilación exhaustiva de actividades prácticas para llevar al aula, pero es mucho más que eso: todas las tareas propuestas conectan con las tres dimensiones comentadas anteriormente, y ello hace que la obra posea una fundamentación y una estructuración impecables.

Así, podemos encontrarnos a modo de ejemplo con una sesión dedicada a la interpretación y elaboración de croquis, planos y mapas. En ella se nos muestra la dimensión matemática, con los distintos conceptos matemáticos implicados en las actividades que aparecerán más adelante, pero complementada además esa dimensión con una serie de aspectos históricos que ayudan a una más adecuada contextualización; se nos presentan las actividades propiamente dichas, incardinadas en una serie de ricas situaciones que hacen que el alumnado no pueda evitar implicarse en ellas; y se nos manifiestan también los aspectos didácticos a tener en cuenta a la hora de llevar a cabo las propuestas concretas de aula, aspectos que articulan y dotan de sentido a todo el proyecto de trabajo.
Y esta estructura unificadora se repite en todos los capítulos del libro, como también aparece en todos ellos un apunte a los correspondientes recursos TIC de interés, como no podía ser menos, máxime en esta época, que las TIC posiblemente estén haciendo que sea la más estimulante intelectualmente de la Historia.

Un apartado importante lo constituye la gran cantidad de materiales didácticos que presenta, cada uno de ellos con su debida fundamentación respecto a las tres dimensiones mencionadas, y con apuntes claros y precisos acerca de los objetivos didácticos plausibles alcanzables con cada uno de ellos, así como con las correspondientes actividades de aula.

Es de agradecer la iniciativa del profesor Nortes Checa y su equipo, y deducimos del título que tienen previsto editar un segundo libro. Si es así, esperamos tener pronto la oportunidad de contar con él, pues con ello se nos hará más sencilla la materialización del que pensamos es el gran objetivo de la Educación en clave de competencias: "priorizar los contextos para dar sentido a los contenidos: partir de la vida para educar para la vida" (Claudi Mans).

Recensor: Eduardo Manuel Zurbano Fernández Universidad de Oviedo (España)

\title{
Cosmopolitismo y Educación. Aprender y trabajar en un mundo sin fronteras
}

\author{
Miguel Ángel Santos Rego (Ed.) (2013). \\ Valencia (España): Brief Ediciones, 221 pp.
}

Hace unos años, en referencia a una obra colectiva sobre "complejidad y educación" ahormada por el mismo editor de las páginas que ahora nos ocupan, escribía que "nuestro tiempo ya del siglo xxi se ha hecho tan plural, intrincado, enredado, antinómico, vario, multiforme, incierto, azaroso, impredecible y cambiante en todos los ámbitos y niveles que queramos y podamos imaginar, y que ni siquiera imaginar podamos, que más que nunca se hace necesario pararnos un momento a meditar y a reflexionar con calma en nuestra relación con él, en nuestro inevitable maridaje"; y añadía entonces: "y en este intrincado pensamiento, de manera forzosa e ineludible, ¡cómo no!, han de situarse siempre también la dimensión y la perspectiva pedagógicas, la educación como proceso complejo y multiforme que ya es, la posibilidad de que pueda haber y de que haya otros modos de entender y de concebir la racionalidad de la acción educativa y su propia y entrañada complejidad".

Al releer ahora aquella reseña, creo que estas palabras se pueden acomodar perfectamente al presente libro por razones varias, pero fundamentalmente por dos: porque, al igual que aquella obra colectiva, ésta, colectiva también, nos mueve, asimismo, a la reflexión sobre el hecho educativo en el mundo en que nos ha tocado vivir y porque esa reflexión nos proyecta ahora hacia el cosmopolitismo como un "modo de entender y concebir la racionalidad de la acción educativa y su propia y entrañada complejidad". Como bien escribe el profesor Santos Rego en la presentación del libro, éste «es el resultado de una invitación a pensar y a compartir ideas, pero también cursos de acción en torno a la agenda educativa de un tiempo que, con sus complejidades e incertidumbres, parece alertarnos sobre la necesidad de confluencias efectivas en la forma de entender el aprendizaje y el conocimiento, más allá de las singularidades cultu- rales pero sin perder de vista lo más genuino de la diversidad, que es, justamente, aquello que otorga valor a una perspectiva cosmopolita merecedora de atención y exploración por cuanto las mejores ansias de los seres humanos seguirán apuntando a la paz y al progreso».

Como obra colectiva que es, la mirada que se ofrece es diversa, multiplicada, caleidoscópica, plural, de matices varios y de ángulos distintos, pero complementarios, que, desde las diferentes atalayas, van descubriendo y desgranando teselas de pensamiento para construir un atractivo mosaico en torno al tema que se aborda: cosmopolitismo y educación; un binomio sin duda necesario en nuestro tiempo y en nuestra sociedad extensa y sin fronteras por cuanto, más allá incluso de otras múltiples consideraciones que podrían hacerse, se ha de ir asentando y maridando cada vez más estrechamente por el propio cumplimiento de la historia que fluye -ahora a menudo también con múltiples y variadas intrahistorias que podemos conocer como en ningún otro momento- y por la propia inercia de los tiempos. No olvidemos, por ejemplo, cómo el flujo migratorio universal -como cruce e interacción de seres humanos, culturas, lenguas, religiones...- no es ya un fenómeno meramente coyuntural, sino un componente estructural, incardinado indefectiblemente en el ser y en el estar de nuestro tiempo y de nuestra sociedad compleja y plural, que nos ha de conducir cada vez más y en mayor medida hacia un interculturalismo que pueda ser enriquecedor y provechoso para la sociedad y para cada uno de sus individuos.

La obra, con la colaboración de profesores de diversas universidades españolas y norteamericanas, se estructura en dos partes. La primera, de impronta más general, acoge cinco trabajos bajo el título de "Cosmopolitismo y Educación para una conciencia global". En ella se encuentran aquellos estudios que buscan presentar una mirada 